\title{
ALTERNATIVAS EN LA ENSEÑANZA DEL ESPAÑOL
}

\author{
DOMINGO LILÓN
}

\author{
Universidad de Pécs
}

Estamos viviendo momentos muy importantes de cambios, transformaciones, no solo en Hungría, sino en una gran parte de países. La educación, en el caso que nos ocupa, la educación superior, no es una excepción. Problemas viejos y nuevos resurgen $y$, naturalmente, hay que tratar de darles respuestas.

Un poco más de dos décadas atrás, quizás más exactamente, hace cinco lustros, la enseñanza y el aprendizaje de lenguas extranjeras vivía una euforia. Tras la eliminación de la obligatoriedad del ruso en las escuelas y las universidades, comenzó un verdadero auge, el interés hacia otras lenguas extranjeras tal cual el español. La creación del Instituto Bilingüe Húngaro-Español Károlyi Mihály de Kispest (1988) marcó un hito en la enseñanza de la lengua española, no solo a nivel de escuela secundaria, sino también universitaria. Ejemplo de ello es la creación de institutos bilingües húngaro-español en otras ciudades de Hungría (Debrecen, Pécs, Miskolc, Szeged, Kecskemét y Veszprém), así como la creación de departamentos de Filología Hispánica en las universidades de Szeged, Pécs y la Católica Pázmány Péter de Budapest.

Cuando iniciamos nuestra relación con la enseñanza de la lengua española y la cultura hispana, en 1989, en Pécs no había ningún centro oficial donde se enseñara el español. En el Instituto Nagy Lajos se podía aprender en unos círculos de estudios extraoficiales. Hoy día, transcurridos ya cinco lustros, podemos decir que la salud del español, su enseñanza y aprendizaje, es muy buena. No solo ha crecido el número de escuelas secundarias (y una primaria) donde se enseña el español, sino también el número de profesores (nativos y húngaros), tal cual podemos ver en el cuadro más abajo.

\begin{tabular}{|l|c|c|}
\hline \multicolumn{1}{|c|}{ Institución } & $\mathbf{N}^{\mathbf{o}}$ de profesores & $\mathbf{N}^{\mathbf{0}}$ de estudiantes \\
\hline $\begin{array}{l}\text { Kodály Zoltán (Sección } \\
\text { Española/formación bilingüe) }\end{array}$ & 9 (3 nativos/6 húngaros) & $220(150 / 70)$ \\
\hline Leöwey Klára & 2 & 124 \\
\hline Babits Mihály & 3 & 120 \\
\hline Waldorf (primaria) & 2 & 85 \\
\hline Nagy Lajos & 2 & 70 \\
\hline Árpád Fejedelem & 1 & 58 \\
\hline Szent Mór & 1 & 40 \\
\hline Deák Ferenc & 1 & $?$ \\
\hline Total & 21 & $\mathbf{7 1 7}$ \\
\hline
\end{tabular}

Instituciones donde se enseña español en Pécs. Fuente propia. 
A ello contribuyó en gran medida la creación en 1990 del llamado Programa de Español desarrollado por el profesor Endre Fülei-Szántó y quien escribe estas líneas, dando lugar más tarde a la creación del Departamento de Español de la entonces Universidad Janus Pannonius de Pécs. Solo dos profesores de español en Pécs no han sido egresados del Departamento de Español de la Universidad Janus Pannonius/de Pécs (excluyendo a los nativos arriba enumerados).

Sin embargo, a pesar de la relativamente positiva información arriba mencionada, no podemos estar satisfechos con la enseñanza y el aprendizaje del español, principalmente si analizamos la situación a nivel regional, puesto que la difusión de la lengua española, su enseñanza y apendizaje, debería de llevarse a cabo en este contexto, a nivel regional. Específicamente, en la Región Transdanubia del Sur formada por las provincias de Baranya, Somogy y Tolna, la fuente principal de origen de los futuros profesores de español de la región.

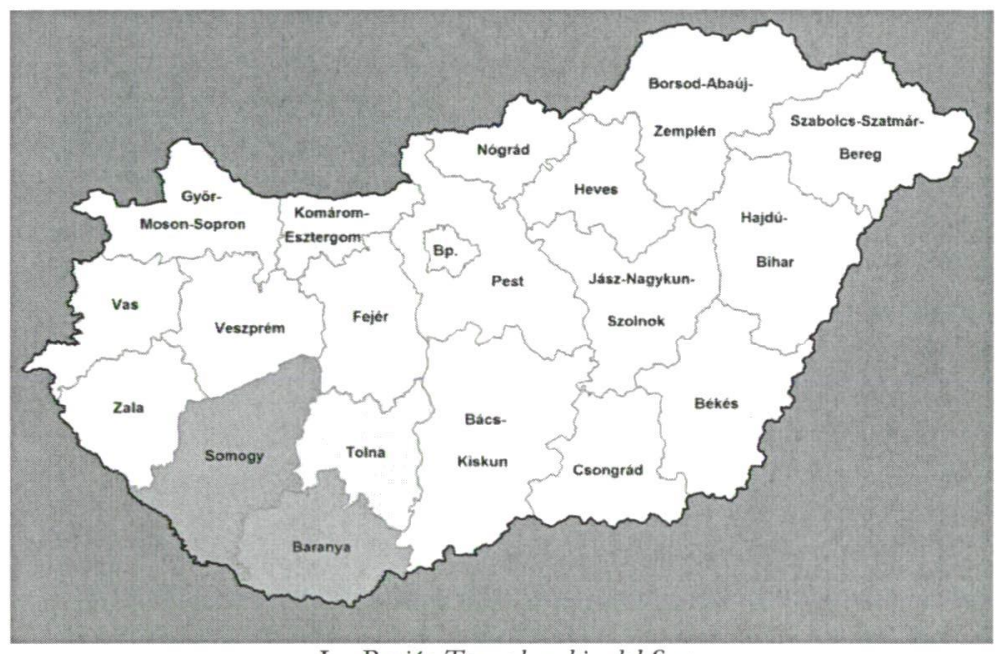

La Región Transdanubia del Sur

En esta región, con un territorio de $14169 \mathrm{~km}^{2}$ y una población cercana al millón de habitantes, además de Pécs, solo se enseña y se estudia el español en Kaposvár, capital de la provincia de Somogy, en los institutos Táncsics Mihály y Munkácsy Mihály. Ambos institutos cuentan con un solo profesor de español. Esto representa un gran problema, puesto que la difusión del español se limita prácticamente sólo a Pécs, existiendo en la región un sinnúmero de institutos donde se podría enseñar el español como lengua extranjera, dando de esta forma salida y oportunidades a los nuevos egresados de la carrera de Filología Hispánica. Naturalmente, conocemos muy bien las dificultades que representa la introducción de una lengua extranjera, desde el aspecto político, económico, cultural y social. 
Otro aspecto del problema al que hay que prestar atención es el promedio de edad de los actuales profesores de español, principalmente en el caso de Pécs. Haciendo un somero ejercicio matemático, consideramos que el promedio de edad de nuestros colegas profesores de institutos ronda entre los 30-35 años, lo que significa que habría que esperar casi toda una generación (y algo más) para que estos sean sustituidos tras llegar a la edad de jubilación. De allí la necesidad de seguir difundiendo la lengua española, su enseñanza en la región Transdanubia del Sur, no sólo para fortalecer la salud misma de la lengua, sino también para dar salida y empleo a los jóvenes profesionales.

\section{Enseñanza del español en la Universidad de Pécs}

No creo ser atrevido al escribir la palabra "crisis" respecto a la enseñanza del español en las universidades, al menos en provincia. Disminuye el número de estudiantes con los problemas (económicos) que esto acarrea. Mucho más en época de grandes cambios y reformas, entre ellas, la educación superior. En vano (no desde el punto de vista académico) la participación del Departamento de Estudios Hispánicos e Iberoamericanos de la Universidad de Pécs en diferentes programas (Historia, Relaciones Internacionales, Antropología, Traducción e Interpretación, etc.), programa minor y demás, cuando el número de estudiantes disminuye y con ello, aumenta el déficit del Departamento. Al fin y al cabo los números son los que cuentan; naturalmente, los positivos.

La no creación de nuevas plazas, sea en Pécs, Kaposvár, así como en toda la región Transdanubia del Sur contribuye al éxodo de estudiantes y/o profesionales de la región principalmente hacia Budapest, ciudad, al fin y al cabo, donde se concentra el mayor número de posibilidades laborales. Contra ésto es difícil luchar y competir.

"Estamos viviendo momentos muy importantes de cambios, transformaciones...", así empezamos nuestro escrito y ello atañe también a la Filología Hispánica. Hace cinco lustros estudiar Filologia Hispánica era, además de un placer y una pasión, una garantía para el futuro profesional. Hoy día ya no lo es, al menos en provincia. Las exigencias de los nuevos tiempos nos marcan o marcarán nuevas pautas. Sin embargo, nuestros programas de estudio de Filología Hispánica parecen hoy no corresponder a las inquietudes y preferencias del momento que estamos viviendo. $Y$ si queremos sobrevivir, tendremos que ajustarnos a las nuevas condiciones, nos guste: o no, intentando mantener el espíritu y el marco de la Filología Hispánica, tan rígido en la mayoría de las veces. De allí nuestra propuesta de reformar, actualizar, dividir, introducir nuestros programas de estudios a áreas que hoy dia son preferenciales. Me refiero al estudio de Lenguas extranjeras y Management, como realiza la Universidad de Limoges, Lenguas extranjeras y Turismo, como la Universidad de Edinburgh, Iberian and Latin American Studies, como la Universidad de Liverpool o Geoeconomia y Estudios Regionales (Geoekonomske $i$ regionalne studije), como la Universidad Megatrend de Belgrado (Serbia), por sólo mencionar algunos ejemplos. No es nada nuevo ya que en Hungría existen instituciones que realizan programas tales (por ejemplo, Budapesti Gazdasági Föiskola/Budapest Business School), pero sí para nosotros, los de Filología Hispánica. 